\title{
¿Por qué decepciona el aniversario 60 de Naciones Unidas?
}

\section{1. "Querida Naciones Unidas"}

Si no queremos desanimarnos tenemos que ver Naciones Unidas como una difícil utopía y, en consecuencia, como una realidad humana hecha de avances y retrocesos y, tal vez, como dos historias paralelas, la de una institución internacional, nacida para unir, y la historia real de unas naciones muy poco solidarias y en continuo proceso de confrontación. Al terminar la $60^{\mathrm{a}}$ Asamblea General de Naciones Unidas, se levanta un interrogante: la decepción o el fracaso de esta cumbre, ¿se debe más bien a la estructura organizativa de la institución o al comportamiento de los 191 estados que la conforman? Los titulares de algunos periódicos avalan este interrogante. "La cumbre de la ONU concluye con resultados modestos y numerosas discrepancias" "La ONU o la Babel necesaria. La soberanía de los 191 países marca los límites a las reformas necesarias y pendientes de Naciones Unidas" (El País, 17 y 18 de septiembre de 2005); "Los líderes mundiales aprueban una tímida reforma de la ONU en la clausura de la cumbre" (El Mundo, 17 de septiembre de 2005); "La difícil reforma de Naciones Unidas" (Le Figaro, 14 de septiembre 2005); "El plan de reforma preparado por la ONU es muy limitado", "Luchar contra la pobreza requiere una reforma de la ONU" (Le Monde, 14 y 18 de septiembre de 2005).

También se encuentran titulares que levantan los ánimos: "Blair: la ONU tiene que hacerse mayor", "Naciones Unidas tiene que hacerse mayor; tiene que ser la expresión visible y creíble de la globalización de la política. O trabajamos juntos o sufrimos aislados". Los efectos "se medirán en las vidas de los millones de personas que jamás escucharán estos discursos o leerán nuestras declaraciones", tanto por lo que se refiere a la ayuda para el desarrollo como al liderazgo que Naciones Unidas debe asumir en la seguridad, "tienen sus orígenes en una ideología nacida a miles de kilómetros de nuestras orillas; jamás detendremos la proliferación de armas nucleares, químicas y biológicas si no hay un consenso internacional para hacerlo; no podremos proteger el medio ambiente o liberalizar el comercio sin una acción eficaz conjunta. Y cuando miramos con repugnancia, como debe ser, la miseria de los millones que mueren en África y otros lugares por hambre, enfermedades y conflictos evitables, la urgencia para actuar no sólo la dicta la conciencia, sino la convicción de que un día, si no hacemos nada cosecharemos terribles consecuencias" (El País, 16 de septiembre de 2005).

Estas reflexiones de Tony Blair recuerdan algunas palabras de Bill Clinton, en el discurso pronunciado en la Cumbre del milenio, cinco meses antes de dejar la Casa Blanca, las cuales han sido interpretadas como su "testamento diplomático": "Aquellos que en mi país, o en cualquier otra parte, creen que podemos prescindir de la ONU o imponer nuestra voluntad sobre ella, malinterpretan la historia y no comprenden el futuro [...] Nos guste o no, somos cada vez más interdependientes. Debemos buscar soluciones y alejarnos de aquellas opciones en que se exige la total derrota de alguien". Clinton afirmó que "la ONU debía protagonizar la lucha contra las guerras, la pobreza y la enfermedad y encabezar el esfuerzo por dotar de educación a todos los niños. La lucha por la 
paz, el bienestar y la salud en la aldea global 'tiene una etiqueta con un precio' y todos los países, incluido Estados Unidos, deben pagarlo". Clinton se refería a la revisión de las cuotas que las naciones más pudientes, según su producto interno bruto, deberían entregar a Naciones Unidas ("Clinton se despide de la política mundial con una vigorosa defensa de las Naciones Unidas", El País, 7 de septiembre de 2000. Cfr. Entorno económico mundial, UCA Editores, 2003, p. 197).

"Querida ONU" titula Le Monde su editorial del 18 de septiembre de 2005. La gran asamblea de los sesenta años de Naciones Unidas "termina sin que se decidan las reformas esperadas. Todavía son muchas las divergencias entre los diversos protagonistas, los países ricos del norte y los países pobres del sur, Estados Unidos preocupados por mantener su preeminencia y los partidarios del multilateralismo, los que defienden el derecho de ingerencia y los defensores de la soberanía de los Estados". Si Naciones Unidas muestra defectos serios, señalados por algunos jefes de Estado - Bush y J. Bolton - también tiene sus grandes ventajas. "La primera de ellas es existir. Sesenta años desde su creación con la Carta de San Francisco, no es un pequeño logro en un mundo donde se han dado tantas conmociones. Después de todo, su predecesora, la Sociedad de Naciones, creada y abandonada por Estados Unidos, entre las dos guerras mundiales, no resistió el ascenso de los totalitarismos".

La segunda ventaja de Naciones Unidas “es ser un lugar de debate, incluso de confrontación, entre estados con frecuencia opuestos en muchos aspectos: intereses nacionales, la tradición, la geografía, la ideología [...] Se puede lamentar que Estados no democráticos tengan ahí su puesto y preferir - tal la tentación norteamericana - una institución donde se encuentren las democracias de tipo occidental. Pero tal reunión, ¿ganaría en eficacia lo que pierde en universalidad? Hay además un 'efecto UN?', que ha actuado incluso sobre George W. Bush. En Nueva York, el presidente norteamericano tuvo, el miércoles 14 de septiembre, un discurso sin el tono maniqueo de sus habituales intervenciones. Admitió que 'la cólera y la desesperación' pueden nutrir el terrorismo. Hizo suyos los objetivos del milenio, en la lucha contra la pobreza. No ha excluido la supresión de las subvenciones para los productos agrícolas norteamericanos, a fin de favorecer el comercio del tercer mundo [...] La calamitosa situación en Irak, la incuria de las autoridades revelada por el huracán Katrina, ciertamente, han obligado a Bush a abandonar una postura arrogante. Quienes esperan más de este $60^{\circ}$ aniversario de Naciones Unidas estarán, sin embargo, decepcionados. Se ha perdido la oportunidad para precisar su responsabilidad en la búsqueda de la paz, del desarme, del desarrollo y de conseguir un Consejo de Seguridad más representativo del mundo actual. El 'realismo' quisiera que este objetivo no se abandone" (Le Monde, 18 de septiembre de2005).

Este editorial de Le Monde inspira nuevas reflexiones para no perder la esperanza, al contemplar los sesenta años de Naciones Unidas, cabe decir que ha habido hombres quienes, con gran tenacidad, han lanzado la semilla de la unión, a lo largo de un siglo XX teñido de dolor y de sangre. Naciones Unidas nació en uno de los momentos de mayor confrontación entre las naciones: en 1945, cuando aún estaba fresco el recuerdo de una de las guerras más crueles, en cuanto a daños humanos, físicos y morales. Se acaba de conmemorar el sexagésimo aniversario del campo de concentración de Auschwitz y de las bombas Hiroshima y Nagasaki. En la conferencia de la paz de Yalta se firmaron los estatutos de "la guerra fría" y se ratificó "la teoría de la coexistencia pacífica" (si vis pacem, para bellum, si quieres la paz, prepara la guerra). El siglo XX comenzó a rasgarse, entre este y oeste; luego, entre norte y sur, entre centro y periferia. A esto se agrega una división que, relativamente, pocas personas logran entender: desde el debate de K. Kaustky con V. Lenín, en 1918, la historia del siglo XX ha sido "la historia de los irreconciliables hermanos socialistas", la vía democrática parlamentaria versus la dictatorial del partido único.

A lo largo del siglo XX, Naciones Unidas refleja la contradicción mundial, la confrontación entre "la fuerza del derecho y el derecho de la fuerza". Su Consejo de Seguridad, una instancia creadora de derecho internacional, está copado por las cinco potencias con bomba atómica, hijas de "la coexistencia pacífica" - Estados Unidos, Francia e Inglaterra versus la Unión Soviética y China. Las ojivas nucleares eran armas disuasivas, de manera que ninguno de los bloques -ideológicamente irreconciliables - se extralimitó en sus prácticas militares. Las políticas gubernamentales se fundamentaron en la atrición, el miedo a las consecuencias de un conflicto nuclear, pero nunca en una contrición, es decir, en la persuasión de que la guerra no es la solución. 
Se detuvieron las guerras atómicas, pero se multiplicaron las guerras civiles, las matanzas étnicas y otras guerras de mal recuerdo, como "el síndrome Vietnam" o las invasiones al estilo de las de Nicaragua, Panamá y Grenada. Históricamente, los cinco miembros permanentes del Consejo de Seguridad han sido los cinco mayores exportadores de todo tipo de armas de destrucción masiva, al mismo tiempo que, unos y otros, atizaban guerras civiles, en todos los rincones del planeta. El tema de la recomposición de este Consejo se presentó, pero no se discutió en la Cumbre del milenio del año 2000. La propuesta fue enviada a la papelera de reciclaje, en la Asamblea General del año 2003 y, lamentablemente, se ha quedado en la vía muerta. Este punto muestra la confrontación entre "fuerza y derecho", al iniciar el tercer milenio, cuando la mayoría de los miembros del actual Consejo de Seguridad no ha ratificado los estatutos de la Corte Penal Internacional (CPI) y se resiste a la reestructuración de dicho Consejo para volverlo más representativo de la población y de la seguridad global.

El ambiente interno de Naciones Unidas es, a primera vista, sofocante e irregular, por no hablar de corrupción. Con todo, hay un equipo de asesores e inspiradores que, no sólo mantienen la llama de la utopía, sino que, además, aglutinan a los representantes de los gobiernos para reflexionar sobre los grandes desafíos mundiales. Baste citar, en plena década de la globalización, las cumbres de la tierra (Río Janeiro, 1992), de derechos humanos (Viena, 1993), de población (El Cairo, 1994), del desarrollo social (Copenhague, 1995), de los derechos de la mujer (1996). Todos estos problemas han alimentado "La declaración del milenio 2000", la 58 Asamblea General de 2003 y la agenda inicial de la asamblea de este año. Además de estos aportes -y aun con las limitaciones señaladas por John Bolton-, Naciones Unidas es una de las pocas instituciones internacionales que - junto con el Foro Social Mundial de Porto Alegre - presentan con la mejor objetividad posible y con una elevada dosis de misericordia los problemas de "las naciones desunidas", en su doble vertiente de la equidad económica y de la paz mundial. He ahí los dos ingredientes del terrorismo, cuya definición nos invita a entallar también la Asamblea General de este año 2005.

\section{2. "Los pobres no pueden esperar"}

El 16 de septiembre, último día de la Asamblea General, el cardenal Angelo Sodano, Secretario de
Estado del Vaticano, pronunció su discurso. De la misma manera que La declaración del milenio, las jornadas de la paz, convocadas por los papas desde hace 38 años, el discurso del cardenal Sodano se centra en la doble problemática de buscar una paz fundamentada en el derecho internacional (ius cogens) y una justicia económica, asentada en los derechos humanos (ius gentium). Un dato importante para leer esta Asamblea General es que Juan Pablo II, en la Jornada de la paz de 1979, dedicada a los derechos humanos, avaló el Tratado de Roma de 1998 y pidió a todos los estados ratificar los estatutos de la Corte Penal Internacional. Algunas de las grandes potencias (que suelen visitar al Vaticano) todavía se niegan radicalmente a ratificar dicho tratado. El discurso de Sodano demuestra que la Asamblea General de 2005 aún no ha terminado.

Naciones Unidas no es ciertamente un súper gobierno. Es más bien el resultado de la voluntad política de cada uno de los países miembros. La gente común, los miles de millones de personas que componen el we the people de la Carta de Naciones Unidas, reclaman, sin embargo, a los responsables de las naciones: dadnos una institución moderna, capaz de tomar determinaciones y de hacerlas respetar. Este es un llamamiento apremiante que llega hasta nosotros por parte de hombres y mujeres decepcionados por promesas hechas y no cumplidas [...] A este respecto, se puede decir que los mecanismos establecidos en los capítulos VI y VII del Estatuto de Naciones Unidas conservan todo su valor y contienen los criterios necesarios para prevenir las amenazas contra la paz y para garantizar la seguridad colectiva. Pero hoy, este marco jurídico debe completarse con los instrumentos jurídicos internacionales necesarios para el desarme y para el control del armamento, para la lucha contra el terrorismo y el crimen internacional y para la cooperación efectiva entre Naciones Unidas y los organismos regionales, a fin de resolver las situaciones de conflicto.

La larga historia de sus operaciones de paz, con sus éxitos y fracasos, ofrece un rico acervo de experiencias para desarrollar parámetros de acciones futuras para la solución de los conflictos. A tal fin, la Santa Sede es favorable a la creación de un organismo para llevar de nuevo la paz a los países que sufren enfrentamientos armados. La Santa Sede es favorable a la Peacebuilding Comisión, que podría planificar y po- 
ner en práctica una ambiciosa estrategia para superar aquellos factores de rivalidades étnicas que son la causa de los conflictos y que pueden volver a serlo en el futuro.

A continuación, el cardenal Sodano parece hacer referencia y avalar las propuestas que Kofin Annan hiciera en su "Discurso ante el plenario de la Cumbre internacional de Madrid sobre democracia, terrorismo y seguridad", el 10 de marzo de 2005. Los objetivos claves de esta cumbre habían sido recogidos en el primer borrador de la agenda de la Asamblea General, incluida una definición de terrorismo, todo lo cual desapareció luego.

Las tragedias acaecidas en los Balcanes, en Medio Oriente y en África, nos deben hacer meditar. Ahora es importante el compromiso que asumamos para fomentar una cultura de prevención de los conflictos, pero también será necesario profundizar bien en el problema del uso de la fuerza para desarmar al agresor. La "Responsabilidad de proteger" trae su origen desde un concepto político y jurídico muy importante [...] Ella nos recuerda, esencialmente, la preeminencia de la dignidad de cada hombre o mujer sobre el Estado y sobre todo sistema ideológico. Por eso, forma parte del conjunto de principios internacionales superiores y fundamentales conocidos como jus cogens. Ante esta reforma de $\mathrm{Na}-$ ciones Unidas, la Santa Sede pide a los estados que tengan la valentía de continuar los debates sobre los modos de aplicación y las consecuencias prácticas del principio de la "Responsabilidad de proteger", con el fin de poner remedio, de manera oportuna, a través del Consejo de Seguridad y siguiendo las indicaciones del Capítulo VII del Estatuto de Naciones Unidas, a aquellas situaciones en las cuales las autoridades nacionales no quieren o no pueden proteger a sus propias gentes, frente a las amenazas internas y externas.

Dirigiendo la mirada al gran tema del desarrollo, debemos reconocer que, en los últimos años, hemos sido testigos de varios gestos prometedores, por parte de los gobiernos. Por ejemplo, la propuesta de nuevos mecanismos para financiar el desarrollo [...] y, en particular, las últimas decisiones tomadas en Gleneagles, por el G-8, son muy apreciadas por la Santa Sede. Pero aún queda mucho por hacer para lograr una movilización económica y financiera solidaria. Esa no puede dejar de tener en cuenta la solución del problema de la deuda de los países más pobres y también de aquellos países de renta media con graves dificultades de endeudamiento externo, fomentando de nuevo la ayuda pública al desarrollo y una generosa apertura de los mercados a favor de los países pobres [...] Los pobres no pueden esperar.

\section{El punto de partida: la Declaración del Milenio}

Durante cinco años, en muchas cumbres mundiales, incluido el Foro Económico de Davos, el punto de referencia han sido los ocho acápites de la Declaración del Milenio, donde tan importante es la letra de sus 39 numerales - "estamos decididos", "nos comprometemos" - como contemplar la desembocadura del siglo XX en el imprevisible cauce del tercer milenio. Kofi Annan comenzó su discurso afirmando, "hay que reinventar Naciones Unidas". En los últimos 55 años, una población de 6000 millones duplica el número de habitantes de 1945, las guerras civiles se han multiplicado y han causado cinco millones de muertos, en los últimos diez años, a lo cual se agregan las limpiezas étnicas, el problema del medio ambiente, la plaga del sida y la malaria y la creciente marea de la pobreza. Annan habló de "una reunión de trabajo" y enunció varios problemas, que comentaremos más despacio. La crisis financiera de Asia 1997, las protestas contra la Organización Mundial del Comercio (Seattle 1999), los acontecimientos de Kosovo, así como el proceso contra Pinochet, son tres simples ejemplos de que estamos viviendo una nueva era.

Qué triste es reconocer que, al terminar el siglo $\mathrm{XX}$, ninguno de los grandes sistemas económicos ha dado una respuesta humana al cúmulo de derechos civiles, políticos y sociales, proclamados en la carta de los derechos humanos de Naciones Unidas. "La globalización es muy beneficiosa para algunos y es potencialmente beneficiosa para todos, pero sólo si los estados trabajan conjuntamente para que estos beneficios lleguen a todo su pueblo". En contraste, miles de millones quedarán abandonados en la pobreza y otros países emergentes están a merced de súbitos cambios económicos. Los desafíos mundiales actuales obligan a trabajar en conjunto. Si esto es cierto en la esfera económica, lo es aún más ante el desafío que representan las matanzas y las guerras. El instinto de solidaridad humana, que impulsa a algunos Estados a acudir en ayuda de los ciudadanos de otros Estados o a pre- 
sentar cargos contra sus antiguos dictadores, es digno de alabanza. Pero cuando estas acciones las aplican uno o algunos estados, en nombre de su propia autoridad, surge el riesgo de la anarquía mundial. Esta es una clara alusión a la "guerra humanitaria" que Estados Unidos y la OTAN libraron en SerbiaKosovo, en 1998, sin autorización del Consejo de Seguridad (Entorno económico mundial. UCA Editores, 2003, pp. 195-196).

Cuando se dice que la globalización es beneficiosa para algunos, pero no para todos, se hace referencia a sucesos recientes. El fallo de uno de los ejes del libre mercado, la crisis financiera mundial de 1997, cuyo epicentro se localizó en el bloque de los "tigres y dragones" sudasiáticos - el modelo presentado por los bancos multilaterales-, sacudió las bolsas de valores y golpeó a países tan distantes y tan distintos como la Rusia de Boris Yeltsin y el Brasil de Fernando Cardoso, fiel discípulo del Fondo Monetario Internacional. En octubre de 1998, James Wolfensohn, presidente del Banco Mundial, pronunció su discurso "La otra crisis", una crisis de pobreza, en los países que perdieron su esperanza. En enero de 1999, los documentos para el foro económico mundial de Davos afirman que "la globalización es irresponsable", porque nadie da la respuesta y nadie se hace cargo de los problemas de pobreza y miseria de fin de siglo. En diciembre de 1999, estalló la protesta de unos 50 mil manifestantes pacíficos, en la reunión de la Organización Mundial del Comercio. Los delegados de los países pobres y emergentes se negaron a firmar un documento final que no habían podido leer. En Seattle se rompió otro de los ejes de la globalización neoliberal, el cual no pudo se restaurado en las cumbres subsiguientes de Doha (Qatar, noviembre de 2001) y menos aún en Cancún (septiembre de 2003), la cumbre del "desarrollo" (ibíd., pp. 137-156 y 258). En la última Asamblea General de Naciones Unidas, hasta el presidente Bush prometió suprimir todas las subvenciones a sus exportaciones agrícolas - si los otros países hacen lo mismo-, para poder avanzar en los compromisos pactados en Doha, antes de la cumbre de Hong-Kong, en diciembre de 2005.

Cuando se cita el acápite tercero de la Declaración del Milenio sobre "El desarrollo y la erradicación de la pobreza", suele hacerse referencia al compromiso de "reducir a la mitad para el año 2015 el porcentaje de habitantes del planeta cuyos ingresos sean inferiores a un dólar por día" (19), con lo cual se dejan en el tintero las causales internacio- nales de esta situación. "El logro de estos objetivos depende, entre otras cosas, de la buena gestión de los asuntos públicos en cada país. Depende también de la buena gestión de los asuntos públicos en el plano internacional y de la transparencia de los sistemas financieros, monetarios, comerciales. Propugnamos un sistema comercial y financiero multilateral, abierto, equitativo, basado en normas, previsible y no discriminatorio" (13). "Que adopten una política de acceso libre de derechos y cupos respecto de virtualmente todas las exportaciones de los países menos adelantados. Que apliquen sin más demora el programa mejorado de alivio a la deuda de los países pobres muy endeudados" (15).

Los documentos para la cumbre del Desarrollo social (Copenhague, 1995) presentaban, en términos estadísticos, tres grandes problemas mundiales en plena era de la globalización: el desarrollo de la pobreza, el crecimiento con desempleo y la insolidaridad y atomización social (ibíd., pp. 8490). Estos problemas están recogidos en el acápite tercero de la Declaración del Milenio.

Más recientemente, los 2500 congregados - los grandes dueños del mundo-, en el foro económico de Davos de este año, seleccionaron seis temas para reflexionar: la lucha contra la pobreza (64 por ciento), una globalización equitativa (55 por ciento), los cambios climáticos (51 por ciento), la educación, el conflicto del Próximo Oriente y el "buen gobierno", en el tercer mundo. Analizaron el estudio preparado por 250 expertos, bajo la dirección de Jeffrey Sachs, "invertir para el desarrollo, un plan práctico para realizar las metas del Milenio 2000" y reducción de la pobreza (y de otras lacras sociales) a la mitad en 2015. Estos objetivos no se están alcanzando, aun cuando el año "2005 es la última alternativa para vencer la pobreza". En este foro económico, donde se actualizó la Declaración del Milenio, Tony Blair tuvo un papel protagónico al dirigirse al nuevo gobierno de Bush, al cual le solicitó que "Estados Unidos se asocie a la lucha contra la pobreza". Pero ningún alto funcionario de este gobierno asistió a la reunión.

Blair afirmó que los desafíos del mundo son interdependientes. Estados Unidos sabe que no puede vencer solo el flagelo del terrorismo y, por ello, debe cooperar en la lucha contra los otros desafíos planetarios. "Si Estados Unidos quiere que el resto del mundo participe en los objetivos que él se ha fijado, Estados Unidos debe, por su parte, participar en los otros objetivos. Es absurdo tener que 
escoger entre una acción que se concentre en el terrorismo y otra sobre la pobreza en el mundo. La lucha antiterrorista, la propagación de la democracia y la paz en el Próximo Oriente son objetivos relacionados entre sí y no pueden disociarse de la ayuda a África, presa de la miseria o de pandemias como el sida o el paludismo o la lucha contra el recalentamiento del planeta, generador de catástrofes. Se puede luchar contra el calentamiento climático sin que ello frene el crecimiento económico, gracias al aporte de la ciencia y de la tecnología" (ECA, 2005 , pp. 226 y 234). Dada la cercanía y la amistad entre Blair y Bush, el discurso del primero aclara un poco el tipo de tensiones que el gobierno estadounidense ha generado, en las cumbres de Naciones Unidas, desde el 10 de noviembre 2001, dos meses después del 11 de septiembre.

\section{El Consejo de Seguridad y la Corte Penal Internacional}

Annan ha insistido en la ratificación, por parte de los Estados, de los estatutos de la Corte Penal Internacional, "que juzgue a los genocidas que los tribunales nacionales no pueden o no quieren juzgar. El mundo estará más seguro si sabe que Naciones Unidas puede intervenir cuando están amenazados con una destrucción masiva. Tenemos que trabajar todos juntos para preservar los recursos naturales de los que depende toda la población de la tierra" (ibíd., p. 196). Clinton estaba dispuesto a firmar el decreto de Kyoto, con el aval histórico de su vicepresidente (Al Gore, La tierra en juego). Asimismo, firmó los estatutos de la Corte Penal Internacional. Pero su sucesor se ha negado a firmar el protocolo de Kyoto de 1997 (para reducir los gases de efecto invernadero), en las cumbres de Génova y Bonn (2001) y en la cumbre de la tierra de Johannesburgo (2002), e incluso en la reunión más reciente del G-8 (Greneagles, Escocia, 2005), porque "El protocolo de Kyoto es malo para la economía norteamericana". Esta negativa se ha repetido durante cinco años, en las cumbres más diversas, pese a que la economía estadounidense causa el 25 por ciento de la contaminación mundial. Más aún, uno de los temas que John Bolton sacó de la agenda de la Asamblea General "la mención de la lucha contra el recalentamiento climático" ("Golpe de fuerza norteamericano contra la reforma de la ONU", Le Monde, 26 de agosto de 2005). El desastre natural previsto y evitable, generado por el huracán Katrina, parece haber abierto algo los ojos a la nomenklatura de la Casa Blanca.
El gobierno de Bush se ha negado, asimismo, ha ratificar los estatutos de la Corte Penal Internacional, ya que considera que "puede ser una herramienta de persecución política contra soldados o civiles estadounidenses, en servicio internacional". Bush tampoco quiere comprometerse a entregar a la Corte a ciudadanos extranjeros, acusados de crímenes de guerra, aun cuando la acción de la Corte Penal Internacional no será retroactiva, sino que tiene jurisdicción sólo sobre los crímenes - de guerra, contra la paz, de lesa humanidad y genocidios - , cometidos después del 1 de julio de 2002. Sus estatutos ya fueron ratificados por 94 de los 191 países miembros de Naciones Unidas. Solo cinco de los quince miembros del Consejo de Seguridad han ratificado sus estatutos; tres de los cinco miembros permanentes tampoco los han ratificado - Estados Unidos, Rusia y China-. El Salvador ha suscrito el Artículo 98, en virtud del cual ni el gobierno de Estados Unidos, ni el gobierno de El Salvador entregarán a la Corte a ningún ciudadano estadounidense o salvadoreño que pudiera ser juzgado por tales delitos. La Asamblea Legislativa ratificó este acuerdo en mayo de 2004.

Annan planteó, en la Cumbre del Milenio, la necesidad de reformar, o más bien de reestructurar, el Consejo de Seguridad, no solo desde el punto de vista cuantitativo, para hacerlo más representativo de los 6 mil millones de habitantes y de los 191 países miembros de Naciones Unidas, sino que también desde el punto de vista de la moral y del derecho internacional. "A menudo, los cinco países con veto culpan a Naciones Unidas de los errores que ellos provocan. Bosnia y Ruanda son solo dos casos; nadie envió cascos azules para evitar el genocidio rwandés, en 1994. Todos desoyeron al propio Secretario General, Boutros Ghali, cuando solicitó, en 1996, una policía internacional para separar asesinos de víctimas en los campos de refugiados hutus, en Zaire. ¿El resultado? La actual guerra de Congo-Kinzaza" ("La cumbre del milenio intenta definir las reglas de juego de la globalización", El País, 5 de septiembre de 2000). Los criterios morales que fundamentan la conducta de este Consejo de Seguridad son aún una cuestión abierta a debate.

El presidente Saca declaró a La Prensa Gráfi$c a$, después de su participación en la Asamblea General, que "Es evidente que en Naciones Unidas hay categorías de países. Es evidente que hay quienes vetan todas las decisiones y así ha sucedido en los últimos 60 años [...] Por eso, yo creo que el Consejo de Seguridad debe ser más participativo, 
incluir a países de más regiones del mundo; por eso, la inclusión de Japón o Brasil debería ser viable. Es de justicia. El terrorismo, la miseria no esperan... y aquí seguimos discutiendo reformas que no llegan". El apoyo para ampliar el Consejo de Seguridad -24 o 26 miembros, entre permanentes y rotativos - es muy importante, pero dos detalles muestran que el gobernante salvadoreño obedece a "la voz de su amo". En efecto, el presidente Saca incluye a Japón y deja fuera a Alemania, porque Estados Unidos no desea tener como miembros permanentes o rotativos a representantes de "la vieja Europa" (Francia y Alemania), contrarios a la guerra contra Irak. Por añadidura, en Alemania occidental florecieron, sucesivamente, dos modelos económicos, la economía social de mercado y el Estado social de bienestar, una alternativa al consenso de Washington. Es imposible defender, sin ningún argumento, el derecho de veto de los cinco grandes, solo porque el delegado estadounidense Bolton impuso no tratar la eliminación de dicho poder de veto ("Las exigencias norteamericanas amenazan la reforma de la ONU", Le Monde, 30 de agosto de 2005). Hacer estas afirmaciones en el mes de la independencia, suena a todo lo contrario. ("Si yo tuviera poder de veto, tampoco lo entregaría", $L a$ Prensa Gráfica, 17 de septiembre de 2005, p. 18). El presidente Saca ignora la serie de delitos contra el derecho internacional cometidos al amparo del privilegio del veto en el Consejo de Seguridad.

En la Asamblea General de septiembre de 2003, se planteó una serie de preguntas que todavía no han tenido respuesta: ¿para qué sirve Naciones Uni-

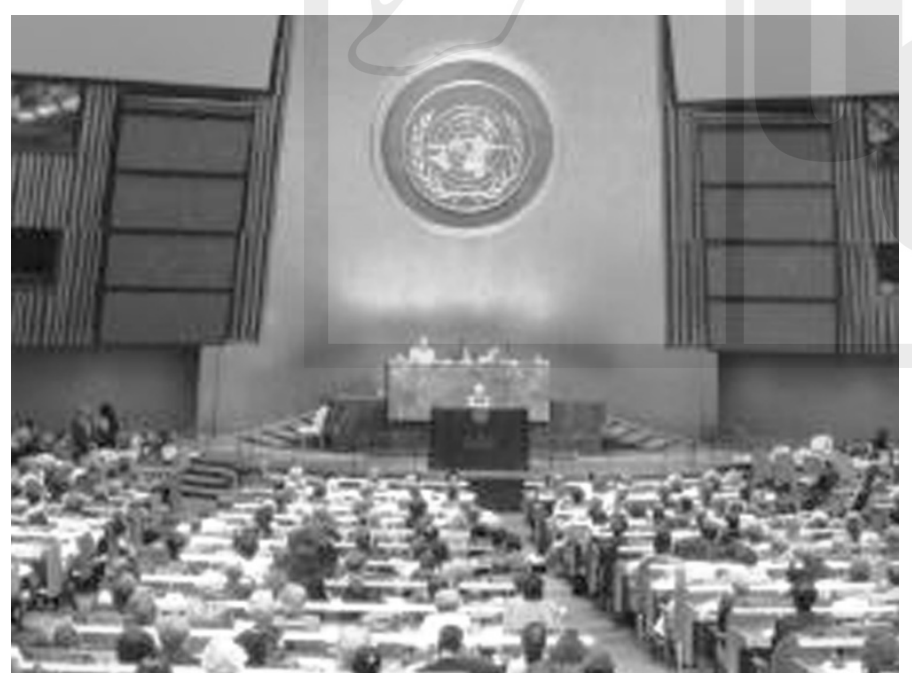

das, si no logra que sus resoluciones sean respetadas?, ¿cuál es la representación del Consejo de Seguridad y cuáles los criterios que le permiten decidir el uso de la fuerza?, ¿hay que conservar el "derecho al veto"?, ¿habrá que pensar en trasladar la sede de Naciones Unidas fuera de Nueva York?, ¿cuál es la responsabilidad de la comunidad internacional, cuando un Estado no protege a sus ciudadanos? ¿Los ciudadanos, ¿deben estar representados en Naciones Unidas?

Respondo a una sola de estas preguntas, la referida al derecho de veto. El 14 de octubre de 2003, justo cuando se desarrollaba la Asamblea General, John Negroponte, embajador de Estados Unidos, vetó una resolución, presentada al Consejo de Seguridad por Siria, en nombre del mundo árabe. La resolución condenaba la construcción del llamado "muro de seguridad, en Cisjordania", por Israel. La construcción era declarada "ilegal de acuerdo a las normas del derecho internacional" y Siria solicitaba, en consecuencia, que el Consejo se opusiera "a todas las actividades de colonización en los territorios ocupados y de todas las actividades que impliquen la confiscación de tierras y su anexión". Negroponte alegó que el texto "no era equilibrado y no condenaba el terrorismo con términos explícitos. Una resolución del Consejo de Seguridad que se queda en la frontera, no permite progresar en el objetivo de llegar a la paz y a la seguridad en la región". Ante ello, cabe preguntarse para qué sirve el Consejo de Seguridad, si la condena es aprobada por diez miembros, pero uno la anula, el representante de un país que, al igual que Israel, se destaca por burlar tradicionalmente las resoluciones de Naciones Unidas. ¡Qué moral la de este embajador de Estados Unidos, para quien "la potencia ocupante" es la víctima, mientras que el pueblo invadido el terrorista!

La historia no termina ahí. El 21 de octubre de 2003, la Asamblea General aprobó detener la construcción del "muro de seguridad", por una aplastante mayoría de 144 votos contra 4 -Estados Unidos, Israel, Islas Marshall y Micronesia- y 11 abstenciones. La declaración afirmaba que el muro israelí "contraviene el derecho internacional" y exigía a Israel detener su construcción y deshacer la parte ya levantada, porque usurpa territorios palestinos. Como las resoluciones de la Asamblea 
General no son vinculantes y solo manifiestan la voluntad de la comunidad internacional, el "muro de la vergüenza" siguió su marcha. El 8 de diciembre de 2003, la Asamblea General trasladó su solicitud a la Corte Penal Internacional, pues consideraba que estaba dentro de su jurisdicción. Luego de las audiencias de febrero de 2004, la Corte emitió una sentencia tampoco vinculante, pero muy severa para Israel. El argumento parte del concepto de territorios ocupados. Según la Resolución 242 del Consejo de Seguridad, la Corte recuerda que la construcción de colonias israelíes en tierras palestinas es ilegal, "por ser territorios ocupados por la fuerza", incluida la zona oriental de Jerusalén. Por lo tanto, el trazado sinuoso del muro, diseñado para introducir, de hecho, a los habitantes de esas colonias, crea otros tantos "hechos consumados", los cuales modifican el equilibrio demográfico al violar el derecho internacional. La Corte afirma que "Naciones Unidas, en particular, la Asamblea General y el Consejo de Seguridad deben presentar las medidas para poner término a la presente situación" (Entorno económico mundial, pp. 306-309).

Poco pueden hacer la Asamblea General y la Corte Penal Internacional, puesto que su poder es solo moral, mientras que el del Consejo de Seguridad es vinculante, para lo cual basta con un voto de uno de los Estados con poder de veto. Aún, algunas potencias parecen gozar del privilegio de lanzar una guerra sin que nadie pueda interponer su veto. El debate moral y jurídico ha vuelto con la guerra contra Irak, la cual se lleva a cabo sin consulta, ni autorización del Consejo de Seguridad. En Irak, como en otros casos, la potencia ocupante es la víctima y las víctimas de la ocupación son los terroristas. El planteamiento de la nueva estructura y de los poderes del Consejo de Seguridad ha quedado, no ha sido retomado en la Asamblea General de este año. Una buena lectura de los hechos sabe descubrir ahí una de las raíces del terrorismo islámico.

Conviene recordar que en La declaración del milenio, precedida por el listado de sus valores y principios, hay un cierto orden de prioridades. En primer lugar, "la paz, la seguridad y el desarme" (810); luego, "el desarrollo y la erradicación de la pobreza" (11-20); siguen "la protección de nuestro entorno común" (21-23); "los derechos humanos" (2425), la "Protección de las personas vulnerables (26); la "Atención a las necesidades especiales de África (27-28) y el "fortalecimiento de Naciones Unidas" (29-32).
La preeminencia del gobierno de Estados Unidos, sin embargo, en todas las cumbres de Naciones Unidas, desde la del 10 de noviembre de 2001, impone un punto en la agenda: "Bush urge a la ONU a sumarse a la batalla contra el terrorismo. Toda una generación tiene hoy el deber de acabar para siempre con una amenaza planetaria. Quien no se sume a esta lucha pagará las consecuencias... Ha llegado el momento de la acción" (Entorno económico mundial, p. 228). Se trata solo del terrorismo islámico del 11 de septiembre de 2001, en Nueva York; el del 11 de marzo de 2004, en Madrid, y el del 7 de julio de 2005, en Londres. No se menciona el del 3 de septiembre de 2004, en Beslan (Rusia), lo cual disgusta mucho a V. Putin, porque los chechenos no son independentistas, sino terroristas. Todos los demás problemas de La declaración del milenio quedan en la vía muerta ante la exigencia estadounidense de luchar contra ese terrorismo. Esto es lo que ha sucedido en la cumbre de este año, donde John Bolton impuso "su terrorismo" como primer punto de la agenda. Asimismo, quiso imponer su definición de terrorismo. Si Naciones Unidas está dividida por una definición, quiere decir que no encuentra solución para la paz y la seguridad, ni tampoco para la justicia y la equidad. Su ausencia es equivalente a terrorismo.

En septiembre 2003, tuvo lugar la 58 ${ }^{\mathrm{a}}$ Asamblea General. El programa de reformas a discutir, presentado por Annan, acabó en la papelera de reciclaje ante la presión del gobierno de Bush, el cual quiso hacer de una potencia ocupante una fuerza multilateral de la Naciones Unidas. Sin embargo, Annan planteó que el tema central era el sistema de seguridad colectiva, heredado de la segunda guerra mundial. Su breve exposición explica qué es lo que ha estado pasando en las asambleas generales, desde noviembre de 2001, “Cómo podrá funcionar [la seguridad colectiva] si las diferentes regiones del mundo no tienen la misma percepción de qué es lo que les amenaza? Estamos de acuerdo sobre la existencia de nuevas amenazas, pero parece que no estamos de acuerdo sobre su naturaleza, sobre la respuesta y, en concreto, sobre cómo dar una respuesta colectiva. Existen lo que yo llamaría amenazas 'duras', las armas de destrucción masiva y el terrorismo; existen también las amenazas 'blandas', la pobreza, la privación, el sida. Con franqueza, si se hiciera un sondeo en todas las regiones del mundo, no estoy seguro de que las armas de destrucción masiva o el terrorismo aparezcan en primer lugar". 
En el discurso de apertura, repitió las mismas ideas. "Tenemos que enfrentar nuevas amenazas, o tal vez antiguas amenazas, combinadas en forma extraña y peligrosa: las nuevas formas de terrorismo, la proliferación de armas de destrucción masiva. Pero, mientras que para algunos es evidente que estas amenazas son el desafío mayor a la paz mundial y a la seguridad, otros se sienten directamente más amenazados por pequeñas armas en sus conflictos civiles, o por lo que se denominan 'amenazas blandas' como la persistencia de la extrema pobreza, la disparidad de ingresos dentro y entre las sociedades, la difusión de las enfermedades infecciosas, el cambio climático y el deterioro ambiental. En realidad, no podemos escoger. Naciones Unidas tiene que enfrentar todos los desafíos, los nuevos y los antiguos, las amenazas duras y las amenazas blandas".

De esta manera, Annan ayuda a la comprensión de lo que se ha estado repitiendo desde noviembre de 2001, no solo en las asambleas generales de $\mathrm{Na}-$ ciones Unidas, sino también en los mismos foros económicos de Davos y en otras cumbres del G-7. Las "amenazas duras" del norte se imponen sobre las "amenazas blandas" del sur, lo cual se ha debido, en el último quinquenio, a la unilateralidad del gobierno de Bush y al capitalismo militar que practica. Esta ha sido la razón del actual fracaso de la Asamblea General de 2005.

\section{5. ¿Improvisación y demasiados puntos de agenda?}

Al comienzo, este comentario cita una serie de titulares de la prensa, que hablan de resultados modestos, de reforma tímida, de discrepancias numerosas y tensión diplomática fuerte de última hora. Daría la impresión de que una cumbre tan importante no hubiera recibido la suficiente atención y preparación de parte de la institución que convocó a 191 jefes de Estado y de gobierno. Naciones Unidas, como institución, no debe ser culpada por estos resultados mediocres. Más bien hay que buscar la explicación en esos dos titulares: "numerosas discrepancias y fuerte tensión diplomática". Hablando de una preparación más inmediata, desde el mes de marzo, Annan presentó los puntos principales que debían ser debatidos en la Asamblea General de este año. "Annan hace un llamamiento al 'multilateralismo efectivo' y a la 'seguridad colectiva' para poder luchar contra las amenazas actuales - guerras, terrorismo, armas de destrucción masiva y crimen organizado - y para recuperar la confianza hacia la institución, dañada por la división que suscitó la intervención militar en Irak, hace dos años y diversos escándalos”. Estos son, en síntesis, los puntos principales del programa inicial.

Había que analizar y optar por las dos alternativas propuestas para ampliar los miembros del Consejo de Seguridad. Desde hace un año, se habían presentado estas alternativas, hechas añicos durante la cumbre. El tema apareció en la cumbre del milenio, pero se decidió tratarlo en la Asamblea General del año 2003. Sería largo y prolijo comentar las discrepancias diplomáticas de la asamblea de este año 2005. "Estados Unidos y China se unen para bloquear la ampliación del Consejo de Seguridad" (El País, 5 de agosto de 2005) y "Se anuncia un tumultuoso debate en torno a la ampliación del Consejo de Seguridad de la ONU" (Le Monde, 11 de julio r4 2005). Las fechas de estos artículos muestran que las tensiones venían de lejos. Los miembros permanentes del Consejo de Seguridad son privilegiados; pero dos de ellos, además, aportan el mínimo a los gastos generales de la institución. Con todo, lo más criticable es que la mayoría de los actuales miembros del Consejo de Seguridad no ha ratificado los estatutos de la Corte Penal Internacional y algunos de ellos podrían ser sentados en el banquillo de los acusados, en un determinado momento. No son las bombas atómicas las que nos van a dar la seguridad.

Tal como se solicitara en Davos de 2005 y en la cumbre del G-8 (Greeneagles), se volvió a insistir en el 0.7 por ciento del PIB para la ayuda al desarrollo y en otros instrumentos similares para disminuir la pobreza y hacer efectiva la reducción de la deuda externa. A los países beneficiarios se les pidió que "combatan la corrupción, refuercen el buen gobierno y adopten políticas para favorecer la participación del sector privado". "El sida", dijo Annan, es una amenaza tan grande como la del terrorismo. A ella se agregan la tuberculosis y la malaria. En este campo, se enfrentan - desde Doha (Qatar) y cancún - dos derechos: el de la propiedad intelectual, reflejado en el precio de los medicamentos y el de los Estados para defender la salud y la vida de sus ciudadanos.

El problema de la mitigación de los efectos de los cambios climáticos no nació en este borrador de la agenda de este año. Desde el informe del Club de Roma, en 1972, Naciones Unidas ha organizado dos cumbres mundiales de la tierra (Río de Janeiro, 1992, y Johannesburgo, 2002). Aquí sobran los comenta- 
rios, porque el gobierno de Bush ha frenado la serie de compromisos para buscar fuentes alternativas de energías limpias. Es lamentable que los huracanes Katrina y Rita hayan hecho reflexionar a La Casa Blanca que también Estados Unidos está sometido a estas fuerzas naturales. Por tal motivo es que se introdujo el punto de "respeto a la naturaleza".

Las negociaciones de la Organización Mundial del Comercio eran otra cuestión, las cuales han fracasado por culpa de los países industrializados del hemisferio norte, donde se inventó y se practica el llamado Consenso de Washington. Basta leer, en cualquier historia económica, el fiasco que supuso la cumbre de Seattle (1999), las reflexiones sobre comercio y desarrollo de UNCTAD (Bangkok, 2000), lo ocurrido en Doha (Qatar) y sobre todo la conducta inmoral del representante estadounidense (Robert Zoellikc) y la de la Unión Europea (Pascal Lamy), en Cancún (2003), para caer en la cuenta de lo que está en juego. En Cancún, estos dos representantes preguntaron a los demás países "¿qué nos ofrecen ustedes paras que nosotros les demos algo?". En el contexto del fracaso de Cancún se tramitó el tratado de libre comercio de Centroamérica con Estados Unidos. ¿Qué puede pasar ahora, en la cumbre de la Organización Mundial (HongKong, 2005), cuando en más de cinco años los países ricos no han hecho nada? ¿Para qué hablar de reducción porcentual de la deuda externa, si las relaciones asimétricas del comercio internacional la elevan geométricamente?

Para evitar la división, provocada a raíz de la intervención militar en Irak, se pidió al Consejo de Seguridad adoptar una resolución en la cual estableciera los principios del uso de la fuerza. Annan sugirió que el documento se apoyara en las previsiones de la Carta (artículo 51 sobre la legítima defensa) y reconociera el derecho al uso de la fuerza preventiva como mecanismo para preservar la paz y la seguridad, incluso en casos de genocidio, limpieza étnica y otros crímenes contra la humanidad. A la hora de considerar la "opción militar", esta propuesta señala que la acción debe ser "proporcional a la amenaza". Propone, además, crear una comisión para la consolidación de la paz. En la 58 a Asamblea General (2003), el Secretario General, fundamentado en el artículo 51 de la Carta, denunció la ilegalidad y la violación del derecho de la guerra en Irak. En suma, los puntos más importantes de la agenda de este año ya habían surgido en las asambleas anteriores. Muchos de ellos fueron enviados a la vía muer- ta. No es, pues, cuestión de Naciones Unidas como "institución", sino de los imperios que quieren pasar por encima de las otras naciones y del derecho internacional. Por ello, el mensaje del cardenal Sodano insistió en el ius cogens y el ius gentium.

Para organizar la lucha contra el temido terrorismo, se pidió al Grupo de los Sabios una definición, que sirviera como punto de partida a la discusión. "Se pide que se refuerce el mecanismo multilateral para la no proliferación nuclear y el desarme, haciendo énfasis en la necesidad de desarrollar instrumentos para atajar el tráfico ilícito de armas. También se propone buscar alternativas a la adquisición de plutonio enriquecido para evitar que pueda ser utilizado con fines militares y una supervisión efectiva del embargo de armas, además de reforzar la autoridad de la Agencia Internacional de la Energía Atómica". En este borrador, Annan planteó dos problemas que - lastimosamente - distrajeron la atención, con lo cual la mayor parte de problemas relacionados con el desarrollo, las pandemias, la degradación ambiental y las asimetrías comerciales fueron dejados de lado. La razón es sencilla, la definición de terrorismo y el control de un 11 de septiembre nuclear son parte de las "amenazas duras", que preocupan a Estados Unidos, a su gobierno y a sus ciudadanía, aun cuando haya que olvidar las "amenazas blandas", que atemorizan a las poblaciones del tercer mundo.

Es imposible para la Asamblea General de Naciones Unidas "entallar" una definición de terrorismo, porque hasta los inicios del tercer milenio, las potencias ocupantes han sido, por lo general, los terroristas y los pueblos invadidos las víctimas. Por ejemplo, el artículo 6 del estatuto del tribunal de Nuremberg (1945) describe el terrorismo con otra nomenclatura: los "crímenes contra la paz" (6a), los "crímenes de guerra" (6b) y los "crímenes contra la humanidad" (6c). A partir de ellos, Naciones Unidas derivó la noción de genocidio. Según estas cuatro categorías, los terroristas son fuerzas ocupantes o grupos étnicos dominantes. En un siglo, esto no ha cambiado (Entorno económico mundial, pp. 64-65). A modo de posdata, cabe destacar que el Premio Nobel de la Paz de este año ha sido concedido a la Agencia Internacional de la Energía Atómica y a su director Mahomed elBaradei.

En razón de satisfacer la curiosidad de algún lector, el grupo de los sabios pidió aclarar que cons- 
tituye terrorismo "todo acto que obedezca a la intención de causar la muerte y graves daños corporales a civiles no combatientes, con el objetivo de intimidar a una población u obligar a un gobierno o a una organización internacional a realizar o abstenerse de realizar un acto". Annan agregó, "considero que esa propuesta tiene una fuerza moral evidente, por lo que insto encarecidamente a los dirigentes mundiales a que se unan para respaldarla, a fin de aprobar el convenio general lo antes posible". Bolton afirmó que había que agregar las palabras "hechas por terroristas", dando a entender que no entraban en la lista Rumsfeld y Wolfowitz. Por eso, Naciones Unidas no ha podido "entallar" ninguna definición de terrorismo.

Hubiera sido más adecuado entregar a todos los delegados un ejemplar del discurso de Annan sobre la democracia, el terrorismo y la seguridad, pronunciado en Madrid, el 10 de marzo de 2005, donde plantea la estrategia de "las cinco des". Primero, disuadir a los grupos descontentos de elegir el terrorismo como táctica para alcanzar sus objetivos. Segundo, dificultar a los terroristas el acceso a los medios para llevar a cabo sus atentados. Tercero, hacer desistir a los Estados de prestar apoyo a los terroristas. Cuarto, desarrollar la capacidad de los Estados para prevenir el terrorismo; y quinto, defender los derechos humanos, en la lucha contra el terrorismo. En el desarrollo de cada una de estas "des" hay propuestas bien interesantes - que ojalá fueran leídas en la Casa Blanca-, aunque para nosotros sean más duras las amenazas blandas.

Si vale la expresión, un tema que descentró la atención de bastantes delegados fue el temor a la proliferación nuclear. El caso más concreto es Irán, miembro del "eje del mal" para el "imperio del bien". El anterior gobierno de Irán había renunciado, en noviembre de 2004, a seguir procesando o enriqueciendo uranio con fines civiles - generación de electricidad - . En mayo, el gobierno dio marcha atrás a esta decisión y rompió los precintos colocados por la Agencia Internacional de Energía Atómica - pero dejó instaladas las cámaras de televisión-. Así, el gobierno iraní anunció su decisión de continuar con el proceso de enriquecimiento de uranio en su central nuclear de Isfahan, siempre con fines civiles, lo cual no contradice el Tratado de No Proliferación Nuclear. Esta decisión se comprende dado que las naciones vecinas disponen de la energía nuclear atómica - Israel, India, Pakistán, China y Corea del Norte-. A ello se agrega que hay quienes dicen que Estados Unidos no hubiera invadido Irak si Saddam Hussein hubiera tenido la bomba atómica.

Tanto Bush como C. Rice presionan a Alemania, Inglaterra y Francia, y a la Agencia Internacional de Energía Atómica para impedir, por todos los medios, que Irán desarrolle energía nuclear, como parte del programa de no proliferación atómica. Es probable que la mayoría, sin ser experta en asuntos nucleares, esté en contra de la proliferación nuclear, aunque solo fuera porque la contaminación ambiental es peligrosa (Realidad 2005, p. 203). Por ello, resulta cínica la postura del gobierno de Estados Unidos, cuando no ha reducido su arsenal de ojivas nucleares, mientras los técnicos militares del Pentágono modernizan su inventario con nombres, cuya traducción española es muy reveladora: "tipos enteramente nuevos de ojivas nucleares", "ojivas revienta búnkeres", "armas nucleares de precisión y baja potencia", "armas nucleares utilizables" y "armas que penetran bajo tierra". Estas armas han sido clasificadas como convencionales, "porque sus objetivos son dispositivos militares". Estas armas, por otro lado, habrían sido legitimadas por el senado estadounidense como de "efectos radioactivos controlados" (E. Subirats E., "Las nuevas armas nucleares y el futuro de la humanidad", El País, 22 de julio de 2005).

El problema es que, por la presión estadounidense y de los tres países europeos, las posiciones del nuevo gobierno de Irán son cada vez más agresivas. "No nos traten a Irán como tratan a Irak o Libia". La respuesta del público ha sido: "Muerte a Estados Unidos. Muerte a Israel y Dios es grande". Por su parte, el impenitente Bush, dirigiéndose a la televisión pública israelí, anunció que no excluye el recurso a la fuerza contra Irán. "Todas las opciones están sobre la mesa. El recurso a la fuerza es la última opción para un presidente. Ustedes saben que hemos hecho uso de la fuerza recientemente para proteger la seguridad de nuestro país". Bush dijo, además, que "no quería recurrir a la fuerza, sino en última instancia para dar seguridad a su país y ofrecer a las personas la oportunidad de vivir en una sociedad libre". Estas palabras nos recuerdan las que oímos, en febrero y marzo de 2003 ("HiroshimaNagasaki, Teherán y la amenaza nuclear", Realidad 2005, 105, de próxima aparición).

El último punto importante del borrador de Annan es el respeto a los derechos humanos, a las libertades fundamentales, a la democracia y al Estado de derecho. Hay que "retomar el principio de la 'res- 
ponsabilidad' a la hora de proteger a la población civil, que recae en primer lugar sobre los propios Estados. Esto requiere reformular la Comisión para los Derechos Humanos y reforzar el trabajo del Tribunal Penal Internacional, que pueda deliberar juntamente con el Consejo de Seguridad" (Sandro Pozzi, "La ONU trata de recuperar el prestigio con la mayor reforma desde su creación", El País, 23 de marzo de 2005. El 21 de marzo de 2005, El País presentó un listado más largo - sin comentario- de los puntos de agenda de la Asamblea General. El 18 de septiembre, este periódico relata una anécdota que dice mucho. Annan recordó que el embajador ruso criticó, en 1997, lo poco que había hecho, en sus primeras seis semanas - "Ha tenido más tiempo del que Dios tuvo para hacer el mundo"-. El Secretario General le respondió, "Sí, pero Dios tuvo una gran ventaja; trabajó solo, sin la Asamblea General, sin los comités y sin el Consejo de Seguridad". Creo que esta anécdota se aplica con más razón a la cumbre del 60 Aniversario de Naciones Unidas.

\section{Las amenazas duras y las amenazas blandas}

La causa fundamental de los enfrentamientos en las sucesivas asambleas generales de Naciones Unidas, desde 2001, es la desintegración, que muchos gobiernos profundizan, entre las llamadas "amenazas duras " y "amenazas blandas". Para algunos estados del norte, "el desafío mayor a la paz y a la seguridad mundial" son las amenazas duras, las nuevas formas de terrorismo y la proliferación de armas de destrucción masiva. "Otros se sienten directamente más amenazados por pequeñas armas en sus conflictos civiles, o por lo que se denominan 'amenazas blandas' como la persistencia de la extrema pobreza, la disparidad de ingresos dentro y entre las sociedades, la difusión de las enfermedades infecciosas, el cambio climático y el deterioro ambiental. En realidad, no podemos escoger. Naciones Unidas tienen que enfrentar todos los desafíos, los nuevos y los antiguos, las amenazas duras y las amenazas blandas".

Las contradicciones internas de Naciones Unidas tienen su origen en el hecho de que potencias más poderosas del norte, desconcertadas por las nuevas formas de terrorismo, las cuales no se adaptan a los manuales convencionales de guerra - fuerzan a la organización internacional a escoger y a centrar su tiempo y su atención en las amenazas que les preocupan, las duras. Al mismo tiempo que fuerzan a Naciones Unidas a desatenderse de las respuestas a las amenazas "blandas", derivadas de la globalización neoliberal, llamada Consenso de Washington. Lamentablemente, esas grandes potencias no acaban de entender que han iniciado una guerra perdida de antemano, porque mientras más descuiden las respuestas a las amenazas blandas, más fortalecen a las amenazas duras.

Dos codirectores del foro económico mundial de 2004, Philipe Bourguignon y Thierry Malleret, al explicar el lema de dicho foro, "Vivimos en un mundo donde no es posible la seguridad sin la prosperidad, ni la prosperidad sin la seguridad", afirmaron que ambos objetivos son inseparables. Asimismo, los problemas globales no pueden resolverse mas que de una manera global, es decir, incluyendo a todos los actores claves en la búsqueda de las soluciones. La seguridad debe entenderse en un sentido amplio, lo que Naciones Unidas llama la "seguridad humana". Los desafíos provocados por el hambre, la pobreza, toda clase de tráficos, la ausencia de un sistema de educación, de salud, de falta de libertad son realmente gigantescos. Cabe aquí recordar, a modo de ejemplo, a las $800 \mathrm{mil}$ personas que murieron el año 2003, en conflictos bélicos; a los 22 millones que murieron por falta de cuidados sanitarios y a los 800 millones que siguen sufriendo hambre. Más de 42 millones de personas padecen de sida y, en 2005, serán 100 millones. A todos interesa mejorar la "seguridad humana", porque es ahí donde se presenta la relación mayor entre seguridad y prosperidad. Si hoy día 1800 millones viven con menos de un dólar al día, ¿es solo problema de ellos? No, es problema de todos. Sin tomar en cuenta la obligación moral, es conveniente que los países ricos ayuden a los países pobres. Vivimos en una aldea global, cada vez más interdependiente. La pobreza y la frustración de los demás se convierten en problema nuestro; la reducción del mercado a nuestros productos y servicios, el aumento de la emigración ilegal, la mayor contaminación ambiental, las enfermedades contagiosas, el fanatismo y terrorismo son problemas de toda la humanidad y de todos los países. Es una pena que la Asamblea General de Naciones Unidas de este año 2005 haya dejado de lado el lema de Davos (2004), "Cooperación, seguridad y prosperidad".

Francisco Javier Ibisate S. J. Catedrático del Departamento de Economía Universidad Centroamericana "José Simeón Cañas" 